\title{
On the phase transitions in $\mathrm{RbIn}\left(\mathrm{MoO}_{4}\right)_{2}{ }^{*}$
}

\author{
Zapart M. B. and Zapart W.
}

Institute of Physics, Technical University of Czestochowa, Al. Armii Krajowej 19, 42-200 Czestochowa, Poland, e-mail: zapart@wip.pcz.pl

Received: 09.09.2012

\begin{abstract}
Ferroelastic phase transitions in single crystals of $\mathrm{Rb} \operatorname{In}\left(\mathrm{MoO}_{4}\right)_{2}$ have been studied by means of polarised light microscopy. Investigations of morphology and temperature evolution of domain structures in three ferroelastic phases of $\mathrm{RbIn}\left(\mathrm{MoO}_{4}\right)_{2}$ have been performed. Orientation of optical indicatrix axes corresponding to refractive indices $n_{g}$ and $n_{m}$ has been found and optical birefringence measured in (0001) plane in the temperature range covering all of the ferroelastic phases.
\end{abstract}

Keywords: ferroelastics, domain structure, birefringence, trigonal double molybdates

PACS: 62.20.D-, 78.20.Fm, 78.20.Ek

UDC: $535.5,548$

\section{Introduction}

Ferroelastics of a family of double molybdates and tungstates described by the general formula $\mathrm{AB}\left(\mathrm{XO}_{4}\right)_{2}$ (with $\mathrm{A}$ standing for alkali metal, $\mathrm{B}$ for trivalent element, and $\mathrm{X}$ for Mo or W) have become an object of extensive experimental and theoretical interest in view of their phase transitions and critical phenomena observed with varying temperature, pressure or mixed crystal composition [1-4].

The object of our present studies is $\mathrm{RbIn}\left(\mathrm{MoO}_{4}\right)_{2}$ that belongs to trigonal subgroup of the double molybdates and tungstates, which is abbreviated hereafter as TDM/T. The TDM/T are isostructural compounds with common crystallochemical features [5]. Crystalline structure of their trigonal high-temperature phases is described by the space group $\mathrm{P} \overline{3} \mathrm{~m} 1$, with one formula per unit cell. This structure is build up from corner-sharing $\mathrm{BO}_{6}$ octahedra connected to $\mathrm{MoO}_{4}$ tetrahedra, with $\mathrm{A}^{+}$ions being situated between layers. The octahedra $\mathrm{BO}_{6}$ centred at $\mathrm{B}^{3+}$ reveal a trigonal symmetry. A strict consequence of their layered structure is a presence of cleavage planes perpendicular to $c$ axis.

Most of the TDM/T compounds undergo phase transitions to ferroelastic phases; the observed structural phase transitions are of a displacive type. They result in either monoclinic $(\mathrm{C} 2 / \mathrm{m}$ or $\mathrm{C} 2 / \mathrm{c}$ ) or triclinic $(P \overline{1})$ systems [6]. The transition from the trigonal phase is improper and is accompanied by a doubling of unit cell along the three-fold axis. In spite of the fact that the crystals have been attracting attention of researchers for many years, there still seem to be a lot of doubts regarding their properties. Recently it has been pointed out that the ferroelastic phases realising in the TDM/T may be simultaneously incommensurate [7-11]. Thus, the crystals may be said to be examples of systems described by a multi-component order parameter.

\footnotetext{
* The materials of this work have been reported at the $2^{\text {nd }}$ Ukrainian-Polish-Lithuanian Meeting on Ferroelectrics Physics (9-13 September 2012, Lviv, Ukraine).
} 
The symmetry reduction occurring between the trigonal and monoclinic phases leads to occurrence of three orientational states $S_{i}(i=1,2$ and 3$)$ separated by two different types of domain walls $W$ and $W^{r}[12-15]$.

Upon lowering the temperature, a sequence of phase transitions has been found in $\mathrm{RbIn}\left(\mathrm{MoO}_{4}\right)_{2}$ crystal, as evidenced by anomalies seen in the electron paramagnetic resonance (EPR) spectra of paramagnetic admixture ions and changes in the ferroelastic domain structure, as well as through dynamical mechanical analysis (DMA) [16-19]. The transition at $T_{1}=163 \mathrm{~K}$ takes the crystal from a trigonal to incommensurate $3 q$ phase, and then to a three-domain $1 q$ state at $T_{2}=143 \mathrm{~K}$. Subsequent transformations have been found at $T_{3}=134 \mathrm{~K}$ and $T_{4}=98 \mathrm{~K}$; this sequence ends up with a transition at $T_{5}=84 \mathrm{~K}$, after which the trigonal symmetry seems to be restored.

The present work deals with polarised light microscopy studies of $\mathrm{RbIn}\left(\mathrm{MoO}_{4}\right)_{2}$ in the temperature region of 77-300 K. Optical birefringence and orientation of the principal axes of optical indicatrix have been investigated, too.

\section{Experimental details}

Our single crystals of $\mathrm{RbIn}\left(\mathrm{MoO}_{4}\right)_{2}$ were transparent and of a good optical quality. They were characterised with a well defined habit, which is typical for the TDM/T crystals. The laboratory system of $X, Y$ and $Z$ axes used here (see Fig. 1a) coincides with the crystallographic system $(X \| 2$, $Z \| \overline{3}$ and the $Y$ axis lies in the mirror plane).

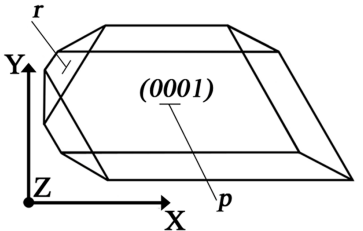

(a)

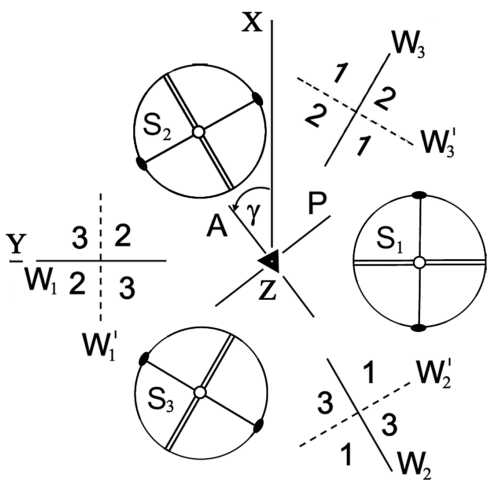

(b)

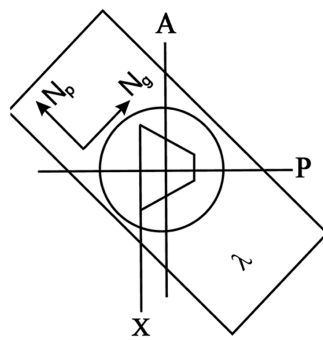

(c)

Fig. 1. (a) Typical habitus of our crystal, with a pinacoid face (0001) marked as $p$ and rhombohedron faces marked as $r$, and a link of laboratory coordinate system $X Y Z$ with crystal morphology. (b) Scheme of domain patterns. (c) Experimental schemes for studying of optical anisotropy.

For examination of ferroelastic domain patterns the samples were prepared in the shape of thin platelets by cleaving as-grown crystals along their (0001) faces. Ferroelastic domains were studied in a wide temperature range, using a polarising microscope Nikon Eclipse LV100POL. It was equipped with a thermooptical stage THMS600 and a Linkam temperature controller. Fig. $1 \mathrm{~b}$ shows point symmetry elements of the three orientational states $S_{i}(i=1,2$ and 3$)$ of the monoclinic phases and a scheme of all orientational variants, with two kinds of permissible domain walls $\left(W_{i} \| m_{i}\right.$ and $\left.W_{i}^{\prime} \| 2_{i}\right)$. Here the angle $\gamma$ defines orientation of crossed polariser $P$ and analyser $A$.

Optical birefringence $(\Delta n)_{Z}$ was measured with a Senarmont compensator for a monochromatic light (the wavelength of $546 \mathrm{~nm}$ ) propagating along the three-fold axis. Here $(\Delta n)_{Z}$ 
represents in fact a morphic birefringence (it is zero in the paraelastic phase, being induced purely by the structural phase transition). The thickness of our sample was $0.19 \mathrm{~mm}$. The measurements were performed in the heating run in the temperature range covering all of the ferroelastic transitions.

A diagram of sample orientation with regard to the polariser $P$, the analyser $A$ and auxiliary plates used during our experiments is shown in Fig. 1. In the past, such an arrangement had been used in order to examine the optical properties of $\mathrm{KSc}\left(\mathrm{MoO}_{4}\right)_{2}$ crystal [15].

\section{Results and discussion 3.1 Ferrroelastic domain structure}

A presence of a number of structural phase transitions in $\mathrm{RbIn}\left(\mathrm{MoO}_{4}\right)_{2}$ has been confirmed by our observations of domain structure performed in the polarised light. As shown in study [18], the phase transition occurring at the temperature of $T_{1}=163 \mathrm{~K}$ is not accompanied by appearance of ferroelastic domain structure. This structure becomes visible not earlier than around the temperature $T_{2}=143 \mathrm{~K}$ and can be observed, with certain modifications, whereas the temperature is lowered down to $T_{5}=84 \mathrm{~K}$. Below this temperature point the domain structure disappears and the crystal, like at the temperatures higher than $143 \mathrm{~K}$, shows no ferroelastic properties [19].

The pictures shown in Fig. 2 reveal the changes in the microscopic image of the crystal in the polarised light observed when the temperature is lowered. It can be seen that the domain structure becomes visible after passing of the phase front at ca. $T_{2}=143 \mathrm{~K}$. A stable lamellar arrangement of domains separated by the $W$-type domain walls is formed in the vicinity of $1 \mathrm{~K}$ below the temperature $T_{2}$; it does not undergo significant reconstruction in the region of phase transition near $T_{3}=134 \mathrm{~K}$. Instead, considerable changes in the domain structure are observed in the vicinity of $T_{4}=98 \mathrm{~K}$. After passing of the phase front, the structure is completely rebuilt and, as a result, large domains separated by the $W$-type domain walls predominate.
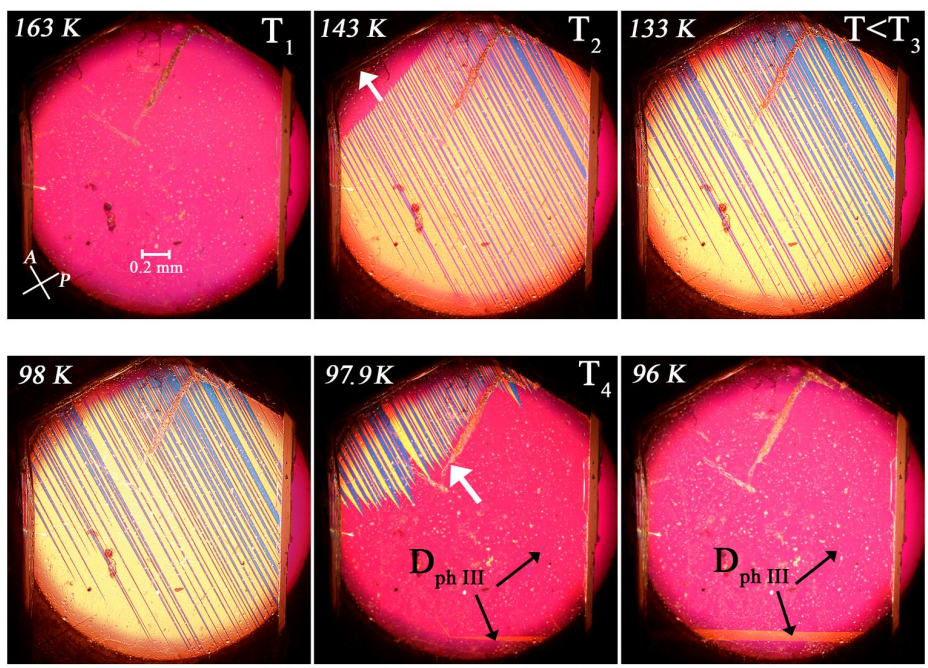

Fig. 2. Formation of ferroelastic domain structure in $\mathrm{Rb} \ln \left(\mathrm{MoO}_{4}\right)_{2}$ observed at $y=30^{\circ}$. Passing of the phase front is marked by a white arrow and domains of the third ferroelastic phase $\left(D_{\mathrm{ph}} \mathrm{II}\right)$ by black arrows.

The domain structure remains stable with further temperature decrease. Around the point $T_{5}=84 \mathrm{~K}$ and again after passing of the phase front, a new phase occurs where the domain structure disappears. Any changes in the orientation of our sample achieved by rotating it around the $Z$ 
axis in the field of view of the microscope below the temperature $T_{5}$ have induced no consequences observed in the polarised light [19]. Hence, the observations in the polarised light provide a strong evidence of three phase transitions happening at the temperatures $T_{2}=143 \mathrm{~K}, T_{4}=98 \mathrm{~K}$, and $T_{5}=84 \mathrm{~K}$. Moreover, the appearance of the phase front testifies to discontinuous nature of these transitions.

However, the ferroelastic domain structure in $\operatorname{RbIn}\left(\mathrm{MoO}_{4}\right)_{2}$ shown above is not the only structure typical for this crystal. A domain structure comprised of two or three types of domains with blurred colours, which continuously change during the observation of the individual domains, is very frequently observed for the same samples in the temperature region 98-143 K, as shown in Fig. 3. Although it is impossible to attribute well defined wall domains to the domain boundaries in the image, the boundary of different shades of colours seems to be parallel to one of the three two fold symmetry axes. Therefore, one can conclude that this type of domain structure is built on the basis of $W^{\prime}$-type domain walls in the temperature region $T_{4}<T<T_{2}$.
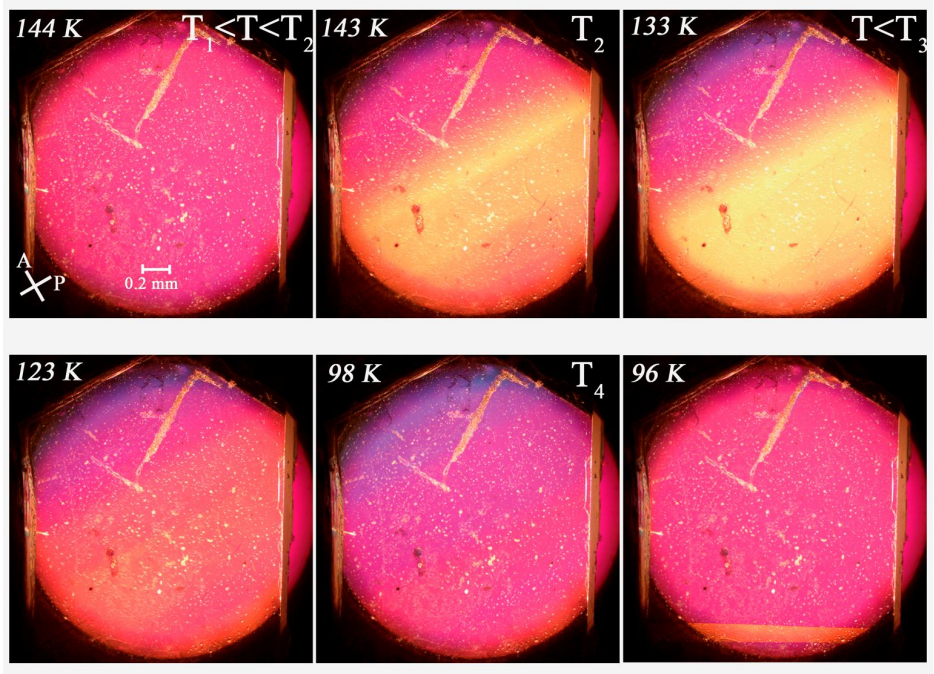

Fig. 3. Temperature evolution of ferroelastic domain structure in $\mathrm{Rbln}\left(\mathrm{MoO}_{4}\right)_{2}$ observed at $y=30^{\circ}$.

The double refraction and the orientation of optical indicatrix axes in the ferroelastic phases presented in the next subsection have been examined only for the first type of the domain structure seen in Fig. 2. It is also worth noting that in many $\mathrm{RbIn}\left(\mathrm{MoO}_{4}\right)_{2}$ samples, the domain structures of the both types coexist in different temperature regions.

\subsection{Optical anisotropy and double refraction}

The presence of the three types of domains (see Fig. 4) observed in all of the ferroelastic phases in the temperatures region from 84 to $143 \mathrm{~K}$ makes it possible to explicitly associate the symmetry elements of the crystal in the monoclinic phase with the walls and edges of the crystal, which is important for correct interpretation of the results observed in the polarised light. It also allows for quick and unambiguous determination of the extinction angle.

Our examination of the extinction angle has enabled us to determine the orientation of optical indicatrix axes that correspond to standard refractive indices $n_{g}$ and $n_{m}$ in all the ferroelastic phases occurring in $\mathrm{RbIn}\left(\mathrm{MoO}_{4}\right)_{2}$ (see Table 1). Their orientation in the phases located in the temperature regions $134-143 \mathrm{~K}$ and $98-134 \mathrm{~K}$ can be summarised as follows: the light polarisation direction corresponding to the refractive index $n_{m}$ is parallel to the two fold axis $\left(n_{m} \| 2\right)$ and that corre- 
sponding to $n_{g}$ lies in the mirror symmetry plane $\left(n_{g} \| m\right)$. However, a change in the orientation of optical indicatrix axes takes place at the phase transition point $T_{4}=98 \mathrm{~K}$ and we have $n_{g} \| 2$ and $n_{m}$ $\| m$ in the ferroelastic phase (i.e., in the temperature region $84-98 \mathrm{~K}$ ). Such orientations of the principal axes of optical indicatrix are expected for the monoclinic arrangement. They indicate that the ferroelastic phase transitions observed in $\mathrm{Rb} \ln \left(\mathrm{MoO}_{4}\right)_{2}$ at $134 \mathrm{~K}$ and $98 \mathrm{~K}$ should separate different modifications of the monoclinically arranged structure.

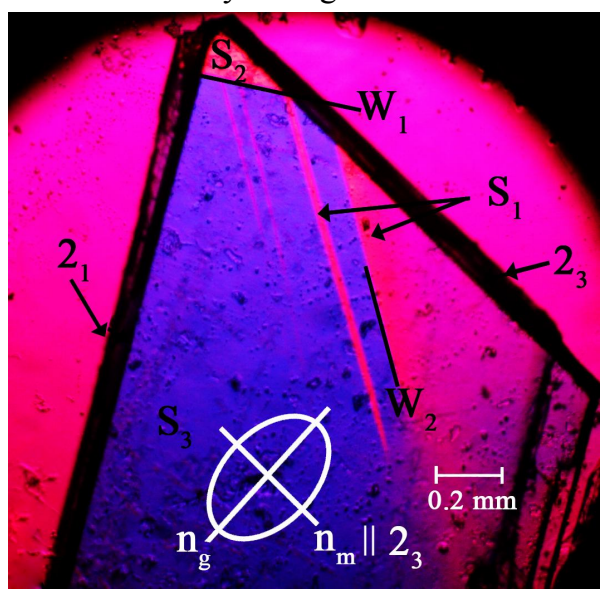

Fig. 4. Ferroelastic domain structure observed in $\mathrm{Rb} \ln \left(\mathrm{MoO}_{4}\right)_{2}$ at $T=115 \mathrm{~K}$, showing a presence of three domain types. Principal axes of optical indicatrix that correspond to the refractive indices $n_{g}$ and $n_{m}$ are shown for the domain $S_{3}$.

Table 1. Orientations of optical indicatrix axes corresponding to the refractive indices $n_{g}$ and $n_{m}$ with respect to the internal symmetry elements of the orientational states typical for the three TDM crystals, as observed in the cross section (0001).

\begin{tabular}{|c|c|c|c|c|}
\hline Crystal & \multicolumn{3}{|c|}{ Ferroelastic phases } & Reference \\
\hline & $\mathrm{I}$ & II & III & \\
\hline $\mathrm{KSc}\left(\mathrm{MoO}_{4}\right)_{2}$ & $\begin{array}{l}n_{g} \| m \\
n_{m} \| 2\end{array}$ & $\begin{array}{l}n_{g} \| 2 \\
n_{m} \| m\end{array}$ & $\begin{array}{l}n_{g} \| m \\
n_{m} \| 2\end{array}$ & [15] \\
\hline $\operatorname{RbIn}\left(\mathrm{MoO}_{4}\right)_{2}$ & $\begin{array}{l}n_{g} \| m \\
n_{m} \| 2\end{array}$ & $\begin{array}{l}n_{g} \| m \\
n_{m} \| 2\end{array}$ & $\begin{array}{l}n_{g} \| 2 \\
n_{m} \| m\end{array}$ & $\begin{array}{c}\text { the present } \\
\text { work }\end{array}$ \\
\hline $\mathrm{KFe}\left(\mathrm{MoO}_{4}\right)_{2}$ & $\begin{array}{l}n_{g} \| 2 \\
n_{m} \| m\end{array}$ & $\begin{array}{l}n_{g} \| 2 \\
n_{m} \| m\end{array}$ & - & [14] \\
\hline
\end{tabular}

One or two structural phase transitions are usually observed in the group of double trigonal molybdates and tungstates. For example, two structural transformations take place at the temperatures $311 \mathrm{~K}[6,20]$ and $139 \mathrm{~K}[21]$ in $\mathrm{KFe}\left(\mathrm{MoO}_{4}\right)_{2}$. Sometimes, like in the case of $\mathrm{KSc}\left(\mathrm{MoO}_{4}\right)_{2}$, there occur three ferroelastic transitions $[6,8]$ (the corresponding temperatures are $T_{1}=260 \mathrm{~K}$, $T_{2}=143 \mathrm{~K}$, and $\left.T_{3}=181 \mathrm{~K}\right)$. In this family, $\operatorname{RbIn}\left(\mathrm{MoO}_{4}\right)_{2}$ seems to show the richest variety of structural phase transitions (the points from $T_{1}$ to $T_{5}$ ), with three different ferroelastic phases. This situation is similar to the case of $\mathrm{KSc}\left(\mathrm{MoO}_{4}\right)_{2}$. For the sake of comparison, Table 1 shows orientations of the optical indicatrix axes $n_{m}$ and $n_{g}$ in the crystals mentioned above, which are characteristic for different ferroelastic phases.

As far as we know, no study has been reported in the literature concerning the double refraction in the $\mathrm{RbIn}\left(\mathrm{MoO}_{4}\right)_{2}$ crystal. As a part of our present studies, we have measured the optical birefringence $(\Delta n)_{Z}=n_{g}-n_{m}$ for the polarised light beam passing parallel to the $Z$ axis. Two transi- 
tions occurring at the temperatures $T_{2}=143 \mathrm{~K}$ and $T_{4}=98 \mathrm{~K}$ are visible owing to abrupt changes in the double refraction, whereas the transition at $T_{3}=134 \mathrm{~K}$ is marked by only a very slight change of the effect size. The characteristic double refraction values typical for the temperatures selected near the phase transitions are gathered in Table 2.

Table 2. Birefringence values $(\Delta n)_{Z}$ for the cross section (0001) measured in the heating run for all of the ferroelastic phases in $\mathrm{RbIn}\left(\mathrm{MoO}_{4}\right)_{2}$.

\begin{tabular}{|c|cc|cc|c|}
\hline \multicolumn{3}{|c}{ Phase I } & \multicolumn{3}{c|}{ Phase II } \\
\hline$T, \mathrm{~K}$ & 143 & 135 & 133 & 100 & 93 \\
\hline$\Delta n, 10^{-4}$ & 1.89 & 2.43 & 2.33 & 2.57 & 1.85 \\
\hline
\end{tabular}

The transition at $T_{2}=143 \mathrm{~K}$ is discontinuous and, when the temperature becomes lower, it is accompanied by a rapid increase in double refraction up to $1.8 \times 10^{-4}$. Further temperature decrease causes only a small change of this value; the birefringence remains almost constant in the temperature region $98-134 \mathrm{~K}$. However, the value mentioned above decreases in an abrupt manner by ca. $30 \%$ at $T_{4}=98 \mathrm{~K}$.

\section{Conclusions}

The earlier EPR investigations have revealed a sequence of structural phase transitions in the $\mathrm{RbIn}\left(\mathrm{MoO}_{4}\right)_{2}$ crystals, starting at $T_{1}=163 \mathrm{~K}$. Nevertheless, the transition to the ferroelastic phase should take place only at $T_{2}=143 \mathrm{~K}$, as evidenced by us through the observation of ferroelastic domain structure. Subsequent transitions, being also ferroelastic, take place at $T_{3}=134 \mathrm{~K}$ and $T_{4}=98 \mathrm{~K}$. The last structural transformation is seen at $T_{5}=84 \mathrm{~K}$ and the ferroelastic domain structure disappears below this temperature point.

The microscopic observations in the polarised light presented in this work provide strong evidence of ferroelastic character of the phase transitions observed earlier by the EPR. The appearance of the phase front at $T_{2}, T_{4}$ and $T_{5}$ reveals a discontinuous character of these transitions. Two types of the domain structure have been found in $\operatorname{RbIn}\left(\mathrm{MoO}_{4}\right)_{2}$, a one with homogeneous domains separated by the $W$-walls and a second characterised by heterogeneous areas with blurred colours, which are bordered by the $W^{\prime}$-walls.

In this work we have presented the first results of crystal optical measurements performed for $\mathrm{RbIn}\left(\mathrm{MoO}_{4}\right)_{2}$ in a wide enough temperature range. We have found the orientations of the optical indicatrix axes in the (0001) plane corresponding to the refractive indices $n_{g}$ and $n_{m}$ for all of the ferroelastic phases (see Table 1). At the temperature $T_{3}$, the orientation of these axes does not change; the same has been observed for $\mathrm{KFe}\left(\mathrm{MoO}_{4}\right)_{2}$, where the transition between two ferroelastic phases occurring at $139 \mathrm{~K}$ involves no changes in the optical indicatrix orientation, the transition being marked only by a small change (namely, a decrease) in the birefringence. With regard to that fact, a decrease in the birefringence observed at the transition between the first and second ferroelastic phases in $\mathrm{RbIn}\left(\mathrm{MoO}_{4}\right)_{2}$ does not seem to be exceptional. A decrease in the birefringence seen at the transition $T_{4}$ between the second and third ferroelastic phases could be closely associated with a total disappearance of the birefringence several degree of Kelvin below (i.e., below the temperature $T_{5}$ ).

Basing on the earlier EPR studies for the admixture ions in $\operatorname{RbIn}\left(\mathrm{MoO}_{4}\right)_{2}$, the monoclinic symmetry $\mathrm{C} 2 / \mathrm{c}$ has been suggested for the first and second ferroelastic phases, and the group $\mathrm{C} 2 / \mathrm{m}$ for the third phase. These suggestions seem to correlate with the earlier findings for the $\mathrm{KSc}\left(\mathrm{MoO}_{4}\right)_{2}$ and $\mathrm{KFe}\left(\mathrm{MoO}_{4}\right)_{2}$ crystals, which state for the monoclinic phases that the principal 
axis $n_{g}$ is parallel to the $m$ plane for the symmetry group $\mathrm{C} 2 / \mathrm{c}$ and the axis $n_{g}$ is oriented along the two-fold axis for the symmetry $\mathrm{C} 2 / \mathrm{m}$.

\section{References}

1. Kaminski A A, 1981. Laser crystals. Berlin: Springer.

2. Aleksandrov K S and Beznosikov B V, 1993. Structural phase transitions in crystals. Novosibirsk: Nauka, and references therein.

3. Hanuza J, Maczka M, Hermanowicz K, Deren P J, Strek W, Folcik L and Drulis H, 1999. Spectroscopic properties and magnetic phase transitions in scheelite $\mathrm{M}_{\mathrm{I}} \mathrm{Cr}\left(\mathrm{MoO}_{4}\right)_{2}$ and wolframite $\mathrm{M}_{\mathrm{I}} \mathrm{Cr}\left(\mathrm{WO}_{4}\right)_{2}$ crystals, where $\mathrm{M}_{\mathrm{I}}=\mathrm{Li}, \mathrm{Na}, \mathrm{K}$, and Cs. J. Solid State Chem. 148: 468-478.

4. Kobets M I, Khatsko E N, Dergachev K G and Kalinin P S, 2010. Electron paramagnetic resonance of rare-earth ions $\mathrm{Yb}^{3+}, \mathrm{Pr}^{3+}, \mathrm{Dy}^{3+}, \mathrm{Nd}^{3+}$ in double molybdates and tungstates. Fiz. Nizkikh Temp. 36: 767-775.

5. Klevtsova R F and Klevtsov P V, 1970. Synthesis and crystal structure of double molybdates $\mathrm{KR}\left(\mathrm{MoO}_{4}\right)_{2}$ for $\mathrm{R}^{3+}=\mathrm{Al}, \mathrm{Sc}$, and $\mathrm{Fe}$, and of the tungstate $\mathrm{KSc}\left(\mathrm{WO}_{4}\right)_{2}$. Kristallografiya. 15: 953-959.

6. Otko A I, Nesterenko N M and Povstyanyi L V, 1978. Phenomenological approach to structural phase transitions in trigonal double molybdates and tungstates, Phys. Stat. Sol. (a). 46: 577-587, and references therein.

7. Zapart W, 1990. Possibility of simultaneously incommensurate and ferroelastic phase in $\mathrm{RbIn}\left(\mathrm{MoO}_{4}\right)_{2}$ by EPR of $\mathrm{Cr}^{3+}$ ion. Phys. Stat. Sol. (a). 118: 477-454.

8. Zapart W and Zapart M B, 1990. Incommensurate phase in $\mathrm{KSc}\left(\mathrm{MoO}_{4}\right)_{2}$ by $\mathrm{EPR}$ of $\mathrm{Cr}^{3+}$. Phys. Stat. Sol. (a). 121: K43-K45.

9. Zapart M B, 1992. Possibility of multi-q state in incommensurate $\mathrm{RbIn}\left(\mathrm{MoO}_{4}\right)_{2}$. Ferroelectrics. 137: 199-203.

10. Zapart M B, 1993. Incommensurate ferroelastics by electron paramagnetic resonance. Ferroelectrics. 141: 67-72.

11. Maczka M, Kojima S and Hanuza J, 1998. Heat capacity measurements of the normalincommensurate and lock-in transitions in $\mathrm{KSc}\left(\mathrm{WO}_{4}\right)_{2}$ and $\mathrm{KSc}\left(\mathrm{MoO}_{4}\right)_{2}$. J. Phys. Chem. Sol. 59: 1429-1432.

12. Otko A I, Nesterenko N M, Krainyuk G G and Nosenko A E, 1983. $\mathrm{KFe}\left(\mathrm{MoO}_{4}\right)_{2}$ and $\mathrm{KIn}\left(\mathrm{WO}_{4}\right)_{2}$ ferroelastic domain structures. Ferroelectrics. 48: 143-148.

13. Otko A I, Krainyuk G G, Stolpakova T M and Nosenko A E, 1984. Domain switching and crystallographic features of monoclinic ferroelastic phases of some double molybdates and tungstates. Izv. Akad. Nauk SSSR, Ser. Fiz. 48: 1116-1119.

14. Dudnik E F, Stolpakova T M and Kiosse G A, 1986. Spatial symmetry and peculiarities of ferroelastic phase transitions in trigonal double molybdates and tungstates. Izv. Akad. Nauk SSSR, Ser. Fiz. 50: 2249-2251.

15. Otko A I, Polomska M, Zapart M B and Zapart W, 1995. Domain structure evolution and phase transition in incommensurate ferroelastic $\mathrm{KSc}\left(\mathrm{MoO}_{4}\right)_{2}$. Ferroelectrics. 172: 299-305.

16. Zapart M B, Stankowski J, Sczaniecki P B and Otko A I, 1979. Anomaly of $\mathrm{Fe}^{3+}$ EPR spectrum in $\mathrm{RbIn}\left(\mathrm{MoO}_{4}\right)_{2}$ monocrystal in the phase transition neighbourhood. Acta Phys. Polon. A. 56: $445-447$. 
17. Zapart M B, Zapart W and Zviagin A I, 1984. Phase transitions in ferroelastic RbIn $\left(\mathrm{MoO}_{4}\right)_{2}$ crystals by electron paramagnetic resonance of $\mathrm{Cr}^{3+}$ ions. Phys. Stat. Sol. (a). 82: 67-73.

18. Zapart W and Zapart M B, 2011. Effect of ferroelastic domain pattern changes on the EPR spectra in TDM. Phase Trans. 84: 872-884.

19. Zapart W, Zapart M B, Schranz W and Reinecker M, 2012. Low temperature phase of the trigonal RbIn $\left(\mathrm{MoO}_{4}\right)_{2}$ crystal. Phase Trans. (online September 11, 2012).

20. Smolenskii G A, Sinij I G, Kuzminov E F and Dudnik E F, 1979. Optical phonons and soft modes in the ferroelastic $\mathrm{KFe}\left(\mathrm{MoO}_{4}\right)_{2}$. Izv. Akad. Nauk SSSR, Ser. Fiz. 43: 1650-1657.

21. Krainyuk G G, Otko A I and Nosenko A E, 1983. Switching of ferroelastic domains in $\mathrm{KFe}\left(\mathrm{MoO}_{4}\right)_{2}$ and related crystals. Izv. Akad. Nauk SSSR, Ser. Fiz. 47: 758-761.

Zapart M. B. and Zapart W., 2012. On the phase transitions in $\mathrm{Rb} \operatorname{In}\left(\mathrm{MoO}_{4}\right)_{2}$. Ukr.J.Phys.Opt. 13: 196 - 203.

Анотація. Методом поляризаційної мікроскопї досліджені сегнетоеластичні фазові переходи в монокристалах $\operatorname{Rb} \operatorname{In}\left(\mathrm{MoO}_{4}\right)_{2}$. Вивчено морфологію $i$ температурну зміну доменної структури у трьох сегнетоеластичних фазах кристалів $\operatorname{RbIn}\left(\mathrm{MoO}_{4}\right)_{2}$. Визначено орієнтацію осей оптичної індикатриси, які відповідають показникам заломлення $n_{g}$ i $n_{m}$ та виміряне оптичне двозаломлення у напрямку перпендикулярному площині (0001) 8 температурній області існування всіх сегнетоеластичних фаз. 